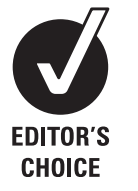

- Additional appendices are published online only. To view these files please visit the journal online (http://pmj.bmj. com).

${ }^{1}$ School of Public Health and Primary Care, The Chinese University of Hong Kong, Lek Yuen Health Centre, Shatin, NT, Hong Kong

${ }^{2}$ Community Rehabilitation Network, Hong Kong Society of Rehabilitation, Pokfulam, Hong Kong

${ }^{3}$ Centre for Health Education and Health Promotion, The Chinese University of Hong Kong, Lek Yuen Health Centre, Shatin, NT, Hong Kong

\section{Correspondence to}

Albert Lee, School of Public Health and Primary Care, The Chinese University of Hong Kong, 4th Floor, Lek Yuen Health Centre, Shatin, NT, Hong Kong; alee@cuhk.edu.hk

Received 3 February 2011 Accepted 23 May 2011 Published Online First 21 June 2011

\title{
General practice and social service partnership for better clinical outcomes, patient self efficacy and lifestyle behaviours of diabetic care: randomised control trial of a chronic care model
}

\author{
Albert Lee, ${ }^{1}$ Choi-Fong Siu, ${ }^{2}$ Kam-Tao Leung, ${ }^{2}$ Louisa C H Lau, ${ }^{1}$ Cathy C M Chan, ${ }^{2}$ \\ Kwok-Keung Wong ${ }^{3}$
}

ABSTRACT
Background The International Diabetes Attitudes,

Wishes, and Needs (DAWN) programmes have shown the existence of a critical gap in self management support and access to the support system. This study aims to evaluate the effectiveness of the diabetes mellitus (DM) self management programme, with partnership between general practice and social work, on clinical outcomes, patient self efficacy and lifestyle behaviours.

Methods In this is single blind randomised controlled trial, subjects were recruited from patients attending general outpatient clinics in the Hospital Authority New Territory East Cluster of Hong Kong. 157 subjects meeting the inclusion criteria completed the study and were randomly assigned to the experimental or control group. The experimental group underwent the six sessions of weekly DM self management course with emphasis on self efficacy and participatory approach. The outcome measurements included $\mathrm{HbA1c}$ concentration, DM self efficacy scale, dietary behaviours, body mass index (BMI), and waist: hip ratio.

Results Baseline assessment observed no significant differences between experimental and control groups for the variables related to outcomes. For the experimental group, the proportion of subjects with normal HbA1c increased from $4.5 \%(3 / 66)$ at baseline to $28.6 \%(19 / 66)$ at week $28(p<0.001)$, but there was insignificant improvement in the control group (3.9\% to $11.8 \%$, $p=0.13$ ). Repeated measure of analysis of variance showed pronounced improvement in DM self efficacy scale and BMl among the experimental group with significant interaction. Dietary behaviours also improved significantly in the experimental group.

Conclusion The DM care model with partnership between general practice and social work demonstrated better diabetic control with improvement of self efficacy and minimisation of risk behaviours.

Trial registration Current Controlled Trials ISRCTN78882965.

\section{BACKGROUND}

Diabetes mellitus (DM) is major cardiovascular risk factor, and maintaining a high degree of glycaemic control is the key to its management. The results of the UK Prospective Diabetes Study (UKPDS) Group advised patients and clinicians of the necessity to lower blood glucose and blood pressure as much as possible. ${ }^{2}$ However, the ACCORD (Action to
Control Cardiovascular Risk in Diabetes) study found no evidence of a lower risk of non-fatal myocardial infarction, non-fatal stroke, or death from cardiovascular causes in the group with median $\mathrm{HbA1c}$ at $6.4 \%$ compared with the standard treatment group with median $\mathrm{HbA1c}$ at $7.5 \%$, and the trial was terminated early because of higher mortality in the intensively treated group. ${ }^{3}$ The ADVANCE (Action in Diabetes and Vascular Disease) study only found a small reduction in total events among the tightly controlled group ( $\mathrm{HbA1c}$ $6.4 \%$ vs $7.3 \%){ }^{4}$ Further analysis of the ACCORD study revealed that patients with poorer glycaemic control had a greater risk of hypoglycaemia, irrespective of treatment group. ${ }^{5} 6$ Those findings highlight the existence of a gap between the quality of care provided and optimal care, despite well known principles of diabetes management. Lifestyles modification such as healthy diet, exercise, weight control, no smoking, and low alcohol intake also help to tighten the glycaemic control. Although advice or education is frequently given in general practice, more extensive patient education programmes emphasising self management skills are generally more effective for improving diabetes control (HbA1c and blood pressure). ${ }^{7}$ Patient self management and patient centred care with emphasis on lifestyle modification should be included as safe and effective ways to control type 2 diabetes. $^{8} 9$

In order to facilitate behavioural changes for more positive lifestyles, knowledge based guidelines might not be sufficient as they lack the motivational and psychological factors. ${ }^{10}$ A self management programme should be built on patient perceived disease related problems, equipping patients with problem solving skills in order to gain self efficacy or confidence in dealing with problems. ${ }^{11}$ A review of studies on 'self-management' training in type 2 diabetes revealed that only a few have contained interventions to enable patients to learn problem solving skills and create action plans, with only a modest improvement in glycaemic control. ${ }^{7}$ Although the Center for Disease Control and Prevention reported that $45 \%$ of patients with diabetes receive formal diabetes education, ${ }^{12}$ not many programmes are evidence based..$^{13}$ A disease specific, self help programme has been shown to have advantages over the more generic programme. ${ }^{14}$

Self efficacy plays a role in the adoption of health behaviours, in the change of detrimental habits, 
and in the maintenance of change. ${ }^{15}$ Findings from an Australian qualitative study suggest that patients with chronic illnesses construct their own individual self management and self care programme springing from an important emotional base. ${ }^{16}$ Self management programmes need to grasp the psychosocial and emotional needs involved in pursuing a meaningful life with chronic illness, ${ }^{17} 18$ and this might explain the small improvement in health outcomes of many lay or peer led programmes developed in the USA ${ }^{19}$ and taken up in the UK. ${ }^{20}$ More research, especially outside Europe and North America, is therefore needed to address the psychosocial perception and self efficacy in chronic disease management.

The aim of this study is to evaluate the effectiveness of a diabetes patient self management programme on clinical outcomes, patient self efficacy, and lifestyle behaviours.

\section{METHOD}

\section{Design and participants}

This was a randomised controlled trial with the assessors blinded. Subjects meeting the inclusion/exclusion criteria were randomly assigned to the experimental group or control group. Both groups received their usual medical follow-ups in their general outpatient clinics (GOPCs), and the experimental group underwent six sessions of a weekly DM self management course (figure 1).

\section{Setting}

The patients attended GOPCs in Hospital Authority New Territory East Cluster of Hong Kong, which is a public service with only a nominal charge for consultation and medication.

\section{Care model}

The model adopted in this project differs from the traditional DM education programme, with a didactic approach which was still widely used in general practice in Hong Kong during the time of the study. Most of the diabetic patients without medical insurance coverage attended the GOPC for care. The GOPC would refer patients with poor control or complications to hospital. The hospital would then refer stabilised cases back to the GOPC. The model was jointly planned by Family Medicine academic discipline and Community Rehabilitation Network (CRN) of the Hong Kong Society of Rehabilitation (HKSR). HKSR is a non-governmental organisation with subvention from the Department of Social Services. Online Appendix 1 outlines the theoretical framework and how the selected concepts are applied as interventions. This programme encouraged the participants to build up healthy behaviours instead of the traditional one-way knowledge based education. It stimulated learning motives by promoting their own problem solving skills related to their personal lifestyles, and tackling the common problems by discussing the everyday caring difficulties encountered and hence constructing a healthy behavioural model. Activities included learning and practising how to use a blood glucose metre; treating low and high values of blood glucose; prevention of complications; taking drugs; and keeping medical appointments properly. Self efficacy enhanced their confidence and ability on self management so they did not get feelings of helplessness with regard to complications. Participants shared the effective strategies for diabetes management during group sessions to relieve their stress on self management during the process of sharing.

The Association of Diabetes Education (AADE) has identified seven self care behaviours through a literature review which

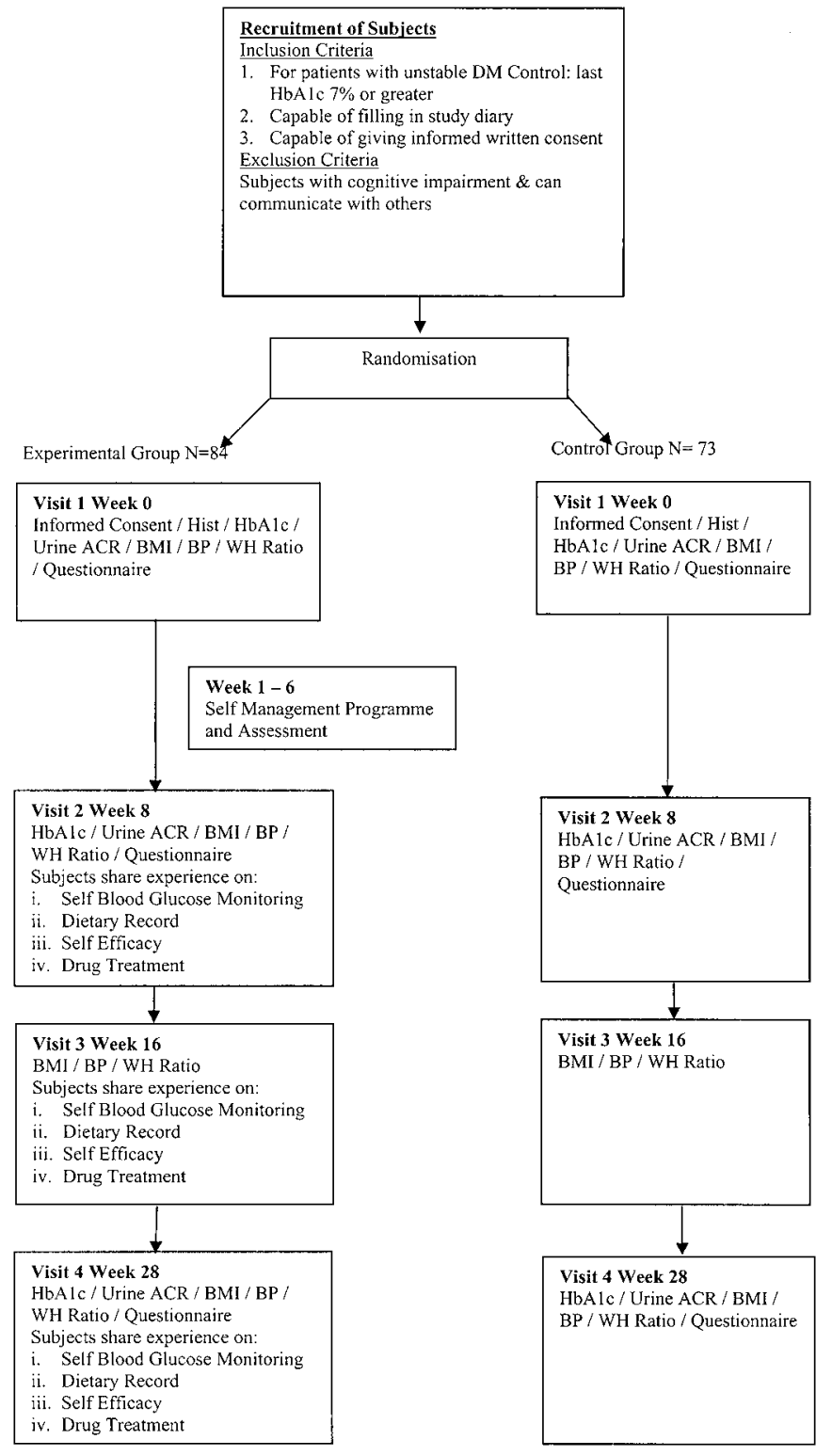

Figure 1 Flow chart of the study. ACR, albumin: creatinine ratio; BMI, body mass index; BP, blood pressure; WH, waist: hip.

evolved to the 'AADE 7' framework, which includes healthy eating, being active, monitoring, medication taking, problem solving, reducing risk, and healthy coping. ${ }^{21}$ Our model has incorporated those core elements. The programme operated on a weekly basis in small groups (around 12-15) for $2.5 \mathrm{~h}$, with an opportunity for individual advice if needed. It has been shown that self care management interventions are more effective with compact programmes, with sessions held close together. ${ }^{22}$ Online Appendix 2 lists the course contents. In this study, the patients' engagement was facilitated by referral of their attending doctors to the programme as part of their treatment regimen. The programme was facilitated by a social worker of the CRN of the HKSR, who had been accredited as a trainer for the self management programme. For the subjects in the control group, they would attend medical follow-up as usual with general advice on lifestyle and drug compliance.

\section{Expected outcomes}

1. An improvement in HbA1c concentrations in patients with unstable DM control 
2. An improvement in blood pressure

3. An improvement in body mass index (BMI)

4. An improvement in waist: hip ratio

5. An improvement in the DM self efficacy scale $e^{23}$

6. An improvement in diet habits

7. An improvement in physical exercise frequency.

The self efficacy scale was developed and validated by one of the authors and consisted of 19 items. $^{23}$ The measurements of dietary habits and level of physical activities were adapted from previous health behaviour surveys conducted locally, with specific items on eating habits such as removing fat from meat, skin from poultry, and consumption of high caloric drinks and snacks, and weekly frequency of moderate and vigorous exercise to avoid answering a long questionnaire. ${ }^{24} 25$

\section{Determination of sample size}

The sample size estimation was based on the primary end point-change in HbA1c in patients with unstable DM control. With the assumption that $5 \%$ of the subjects in the control group would have a successful outcome (ie, HbA1c $\leq 7 \%$ ) and the experimental group would achieve $20 \%$ (effect size) absolute improvement (ie, $25 \%$ of the subjects in the experimental group) with the power of $80 \%$ and significance level of 0.05 (two-sided), taking into account a $20 \%$ dropout rate, it was aimed to recruit at least 118 patients with unstable DM control to meet the sample size requirement.

\section{Data collection}

If a subject fulfilled the inclusion criteria after assessment, he or she was invited to attend a DM care seminar. The objectives and procedures of the study, and their rights, were explained. Written consent was obtained from those subjects willing to participate. The subjects were then assigned to either the experimental or control groups by simple randomisation. The experimental group attended the six sessions of DM self management service based on the care model discussed earlier. They all followed a schedule for periodic assessment and collection of data (online appendix 3). The study was approved by Joint University and Hospital Authority NT East Cluster Clinical Research Ethics Committee.

\section{Data analysis}

Data were processed to give group mean values and SDs where appropriate. Student t test was utilised for continuous variables and McNemar's test for categorical variables. Otherwise the possible intergroup differences were assessed by the Mann-Whitney test. For the change in the primary and secondary outcome measures on week 1-28, repeated measure analysis of variance was performed. If any significant difference was detected, possible interaction effect was also assessed. Group differences with an error probability of $<5 \% \quad(p<0.05)$ were considered statistically significant. SPSS 13.0 for Windows was used for statistical analyses.

\section{RESULTS}

A total of 171 patients meeting the criteria were randomly assigned to the experimental and control groups (figure 1). During the first visit, 84 subjects in the experimental group and 73 in the control group turned up, giving the final sample size of 157, and they attended all the sessions. No statistical significant difference was observed between the experimental and control groups for the main demographic characteristics (table 1). Valid data were collected from 66 and 51 patients from
Table 1 Distribution of sociodemographic characteristics in experimental and control groups

\begin{tabular}{lcll}
\hline & Control (73) & Experimental (84) & p Value \\
\hline Gender-male & $36.90 \%$ & $39.10 \%$ & 0.77 \\
Marital status-married & $79.40 \%$ & $81.40 \%$ & 0.78 \\
Employment status-retired & $42.20 \%$ & $38.40 \%$ & 0.53 \\
Education-secondary or above & $45.80 \%$ & $48.80 \%$ & 0.62 \\
Chronic illness & $64.30 \%$ & $59.30 \%$ & 0.50 \\
Hypertension & $51.20 \%$ & $44.20 \%$ & 0.94 \\
Smoking & $8.40 \%$ & $4.70 \%$ & 0.50 \\
On DM drug & $91.70 \%$ & $90.80 \%$ & 0.84 \\
Spouse with DM & $48.80 \%$ & $42.40 \%$ & 0.41 \\
Relatives with DM & $48.80 \%$ & $42.40 \%$ & 0.40 \\
\hline
\end{tabular}

$\mathrm{DM}$, diabetes mellitus.

the experimental and control groups, respectively, for HbA1c measurement as some patients did not attend for blood tests. No statistical significant difference was found between the experimental and control groups, with an incomplete set of valid data for HbA1c. For other measurements, valid data were collected from most of the patients and the number for the experimental and control groups with valid data were reported in the figures and tables for each measurement.

Patients with $\mathrm{HbA1c}<6.5 \%$ improved notably for the experimental group, from $4.5 \%$ at baseline to $22.7 \%$ during visit 3 at week 16 and $28.8 \%$ during visit 4 at week 28 , with statistical significance (table 2). The mean HbA1c dropped from $8.18 \%$ (95\% CI $7.82 \%$ to $8.54 \%$ ) at baseline to $7.22 \%$ (95\% CI $6.93 \%$ to $7.49 \%$ ) at visit 3 and was maintained at visit 4 . The improvement in HbA1c was not found to be significant for the control group (table 2). The mean differences in DM self efficacy score in the experimental group from visit 1 to visit 2, visit 3 and visit 4 are all significantly larger than for the control group (figure 2). Significant differences in the decreases of BMI were found between the experimental and control groups from visit 1 to visit 2 (intervention group from 25.1 to 24.5 , control group from 25.6 to $25.5 ; \mathrm{p}=0.001$ ) and visit 1 to visit 3 (intervention group from 25.1 to 24.7 , control group 25.6 to 25.6 ; $\mathrm{p}=0.012$ ) (table 2). Significant differences between the experimental and control groups were observed in the decreases of waist: hip ratio from visit 1 to visit 4 (intervention group from 0.92 to 0.9 , control group from 0.92 to $0.93, \mathrm{p}=0.01$ ) (table 2 ).

From the dietary record, the following changes were observed. Among the experimental group, $67.1 \%$ of subjects removed skin from poultry at baseline and increased to $82.3 \%(\mathrm{p}=0.01)$ during visit $2,81.6 \%$ during visit $3(\mathrm{p}=0.01)$, and $81 \%$ during visit 4 $(p=0.01)$. For the control group, $71 \%$ did so at baseline and $73 \%$ during visit 4 with no statistical significance. Regarding removing fat from meat in the experimental group, $56.9 \%$ did so at baseline and increased to $75.4 \%(p=0.02)$ during visit $2,83.1 \%$ during visit $3(p=0.001)$, and $72.3 \%$ during visit $4(p=0.08)$. For the control group, $70 \%$ did so during baseline and $72 \%$ during visit 4, with no statistical significance. No statistically significant results were found regarding changes in blood pressure and exercise level for both the intervention and control groups.

\section{DISCUSSION}

This study has shown that significant improvement in self efficacy parallel improvements in clinical outcomes as measured by $\mathrm{HbA1c}$, BMI, and waist: hip ratio, as well as lifestyle changes such as eating habits. Most of the improvements were still sustained at 28 weeks, months after the completion of the programme. The Diabetes Health Disparity Collaborative 
Table 2 Comparison of clinical outcomes between experimental and control groups. () numbers in each group

\begin{tabular}{|c|c|c|c|c|c|c|c|}
\hline \multirow[b]{2}{*}{$\begin{array}{l}\text { Proportion of normal } \\
\text { HbA1c }(<6.5)\end{array}$} & & \multicolumn{3}{|l|}{ Control group } & \multicolumn{3}{|l|}{ Experimental group } \\
\hline & & $\begin{array}{l}\text { v1, } 0 \text { week } \\
\text { HbA1c }\end{array}$ & $\begin{array}{l}\text { v3, } 16 \text { weeks } \\
\text { HbA1c* } \dagger\end{array}$ & $\begin{array}{l}\text { v4, } 28 \text { weeks } \\
\text { HbA1c* }^{*}\end{array}$ & $\begin{array}{l}\text { v1, } 0 \text { week } \\
\text { HbA1c }\end{array}$ & $\begin{array}{l}\text { v3, } 16 \text { weeks } \\
\text { HbA1c* } \S\end{array}$ & $\begin{array}{l}\text { v4, } 28 \text { weeks } \\
\text { HbA1c* }\end{array}$ \\
\hline Abnormal & Count $\%$ & (49) $96.1 \%$ & (45) $88.2 \%$ & (45) $88.2 \%$ & (63) $95.5 \%$ & (51) $77.3 \%$ & (47) $71.2 \%$ \\
\hline Normal & Count $\%$ & (2) $3.9 \%$ & (6) $11.8 \%$ & (6) $11.8 \%$ & (3) $4.5 \%$ & (15) $22.7 \%$ & (19) $28.8 \%$ \\
\hline Total & Count $\%$ & (51) $100.0 \%$ & (51) $100.0 \%$ & (51) $100.0 \%$ & (66) $100.0 \%$ & (66) $100.0 \%$ & (66) $100.0 \%$ \\
\hline Mean value $(95 \% \mathrm{CI})$ & & $8.04(7.73$ to 8.35$)$ & 7.62 (7.33 to 7.91$)$ & 7.47 (7.22 to 7.72$)$ & $8.18(7.82$ to 8.54$)$ & 7.22 (6.93 to 7.49$)$ & $7.2(6.93$ to 7.49$)$ \\
\hline \multirow[t]{2}{*}{ Mean value } & & $\begin{array}{l}\text { WHR } \\
(69)\end{array}$ & $\begin{array}{l}\text { WHR } \\
(69)\end{array}$ & $\begin{array}{l}\text { WHR } \\
(69)\end{array}$ & $\begin{array}{l}\text { WHR** } \\
(84)\end{array}$ & $\begin{array}{l}\text { WHR } \\
(84)\end{array}$ & $\begin{array}{l}\text { WHR } \\
(84)\end{array}$ \\
\hline & & 0.92 & 0.92 & 0.93 & 0.92 & 0.93 & 0.90 \\
\hline \multirow[t]{4}{*}{ Mean value } & & V1, 0 week & V2, 8 weeks & V3, 16 weeks & V1, 0 week & V2, 8 weeks & V3, 16 weeks \\
\hline & & $\mathrm{BMI}$ & $\mathrm{BMI}$ & $\mathrm{BMI}$ & BMI†† & BMI†† & BMI†† \\
\hline & & $(73)$ & $(73)$ & $(73)$ & $(84)$ & $(84)$ & $(84)$ \\
\hline & & 25.6 & 25.5 & 25.6 & 25.1 & 24.6 & 24.7 \\
\hline
\end{tabular}

*p values for McNemar's test.

†Between first visit and third visit for the control group, $p=0.125$.

$\neq$ Between first and the fourth visit for the control group, $p=0.125$.

$\S$ Between first visit and third visit for the experimental group, $p=0.001$.

Between first and the fourth visit for the experimental group, $p=0.001$

${ }^{* *}$ Significant difference between control and experimental groups was observed in the decreases in waist: hip ratio from v1 to v4 ( $p=0.011$ ).

$+\uparrow$ Significant differences between the experimental and control groups were observed in BMl from v1 to $v 2$ ( $p=0.001)$ and $v 1$ to $v 3$ ( $p=0.012)$.

$\mathrm{BMI}$, body mass index; WHR, waist hip ratio.

project in the USA demonstrated improvement in HbA1c using a chronic care model emphasising patient self management, redesign of the delivery system, decision support, and collaborative learning sessions, and self efficacy and perception of control were found to be significantly associated with better HbA1c concentration. ${ }^{26}$ The implementation of the chronic care model requires a major redesign of medical practice; this programme has taken the initial step of engaging professionals outside the traditional boundary of primary care to build on the self efficacy theory, including all the important attributes for enhancing patient confidence to manage the problems and in so doing form the basis of a successful self management programme, ${ }^{1127}$ rather than just self monitoring which has been shown to be not very useful. ${ }^{28}$

Although lifestyles factors such as exercise, healthy eating habits and smoking cessation would improve diabetes control, compliance with lifestyle modification is more difficult to achieve than drug compliance, as reflected by low participation of patients in health promotion programmes for chronic illnesses. ${ }^{29}$ The intention to change by patients and maintaining those changes will depend on having the 'tools' to do so, as well as believing that the changes are achievable and worthwhile. ${ }^{26}$ This programme closely resembles the concept of health coaching which motivates behavioural change through a structured, supportive partnership with patients. ${ }^{29}$ It helps patients to explore and resolve ambivalence. This programme would fulfil the needs of patients and/or families regarding eating habits, portion sizes, measurement of fats and carbohydrate contents, value of exercise and diet in balance with medications, different medications for diabetes, warning signs of hypoglycaemia, and blood glucose monitoring. ${ }^{30}$ This is particularly important for Chinese or Asian patients who are usually less proactive in adopting lifestyle changes for chronic disease management.

Greater motivation by attending physicians would help as a high assessment of support by providers was associated with better performance of self management. ${ }^{31}$ A major change in the behaviour of medical professionals is needed in order that they can become expert in helping patients to solve their own problems, rather than simply providing treatment. ${ }^{26}$ Health professionals tend to focus more on giving advice and providing education, with less attention paid to psychosocial issues. ${ }^{32}$ The inclusion of social service providers in this study would help to
Figure 2 Self efficacy scores of the four visits for both control $(C, n=70)$ and intervention $(E, n=82)$ groups. The mean differences in DM SES from $v 1$ to $\mathrm{v} 2, \mathrm{v} 3$ and $\mathrm{v} 4$ of experimental group are all significant larger than those of control group.

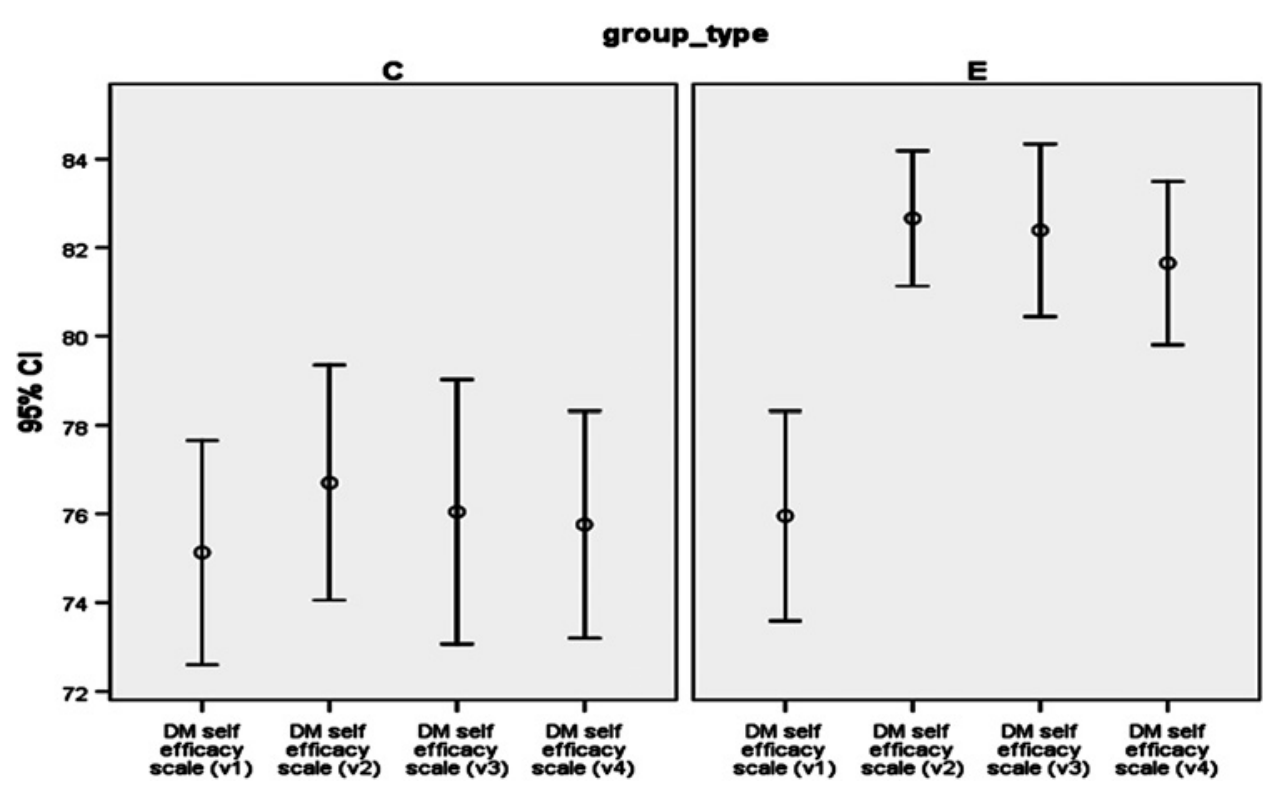


bridge this gap as they are usually engaged in social benefits for patients rather than direct provision of care. That might explain why this programme demonstrated a significant lowering of HbA1c (nearly 1\%), while the meta-analysis of self management programmes of type $2 \mathrm{DM}$ by Norris found only limited evidence of lowering of $\mathrm{HbA1c}{ }^{9}$ with $0.36 \%$ improvement found in the recent meta-analysis by Minet et al. ${ }^{24}$

Health professionals might even devalue the importance of social support that people draw on to self manage their conditions. $^{33}$ In this study the attending doctors had attended a seminar on patient self management so they could emphasise the importance of referral for self management for better control. One study has revealed that high ratings of general practitioner (GP) communication enhanced self monitoring of blood glucose when patient self efficacy was high, but impeded self monitoring when self efficacy was low. ${ }^{34}$ A study conducted on a large healthcare system of enhanced primary care showed a lower degree of improvement in diabetes care (HbA1c reduced from $7.86 \%$ to $7.41 \%$ ). ${ }^{35}$ A paradigm shift towards partnership care consisting of two main components-collaborative care and self management education, that are conceptually similar but clinically separable-would facilitate better clinical outcomes. ${ }^{36}$ GPs should therefore be more sensitive to patients with low self efficacy and encourage them to attend self management programmes aimed at raising their self efficacy, rather than stepping in to take over the entire process.

The findings of this study provide further evidence for Hong Kong and other Asian countries to drive the paradigm shift of the healthcare delivery model from a very 'doctor centred' approach towards being more 'patient centred', with more emphasis on medical education and community care rather than mainly hospital based management. The findings also provide outcome data reflecting the effectiveness of the chronic care model to those healthcare professionals who spend most of their training time in the acute medical model of care, with little understanding and appreciation of how this type of partnership can result in better care for patients. The real world practice might not have given strong consideration to interventions that would improve patient empowerment and lifestyle modifications, with greater support in patient self management resulting in a suboptimal proportion of diabetic patients reaching their desirable targets. Diabetic programmes in Cambodia consisting of outpatient clinics with GPs, nurses, drug educators, and adherence counsellors showed significant clinical improvements in glycaemic control, but only a relatively low proportion of patients reached their treatment targets. ${ }^{37}$ A study on AfricanAmerican adults has shown the importance of incorporating the empowerment principles in supporting DM patient self management in 'real world' settings. ${ }^{38}$ The DESMOND study in UK has demonstrated changes in perceived personal responsibilities, with lower scores of depression and lifestyle improvement among the intervention group subjects, although there was no significant difference in $\mathrm{HbA1c}$ after adjustment. ${ }^{39}$ One must take into consideration that the majority of diabetes patients in the UK have had their biomedical variables recorded and translated into good clinical outcomes, but not many countries in this part of the world would achieve this target. Therefore, an active diabetes self management programme is very much needed.

There are limitations to this study. There were some patients without valid data of $\mathrm{HbA} 1 \mathrm{c}$ across the study period, and fortunately the sample size still exceeded 95 to achieve a power of $80 \%$. No significant difference was observed between the intervention and control groups among those patients. A longer

\section{Main messages}

This randomised controlled trial of diabetes self management, concentrating on self efficacy and development of a healthy behavioural model, demonstrated statistically significant changes in clinical outcomes and health behaviours in the experimental group.

- Patient self management would help achieve better glycaemic control and avoid the adverse effects of intensifying drug treatment for all patients.

- Raising self efficacy and the self construction of a healthy behavioural model is feasible and acceptable in the general practice setting in partnership with social work professionals, and also in an oriental culture with the dominance of doctor centred care.

- GPs should reinforce self management to avoid patients with chronic illnesses fostering a dependence on professionals.

\section{Current research questions}

- Qualitative data should be collected to investigate how such a programme would help patients to improve their diabetes care.

- A longer period of follow-up would provide more evidence on sustainability.

\section{Key references}

- Norris SL, Engelgau MM, Narayan KM. Effectiveness of selfmanagement training in type 2 diabetes: a systematic review of randomised controlled trials. Diabetes Care 2001;24:561-87.

- Wagner EH, Austin BT, Von Korff M. Organising care for patients with chronic illness. Midbank 0 1996;74:511-44.

- Furler J, Walker C, Blackberry I, et al. The emotional context of self-management in chronic illness: a qualitative study of the role of health professional support in the self-management of type 2 diabetes. BMC Health Serv Res 2008;8:214. http:// www.biomedcentral.com/1472-6963/8/214.

- Bodenheimer T, Wagner EH, Grumback K. Improving primary care for patients with chronic illness: the chronic care model, part 2. JAMA 2002;288:1909-14.

- Bodenheimer T, Lorig K, Holman H. Patient self-management of chronic disease in primary care. JAMA 2002;288:2469-75.

period of follow-up would provide more evidence on sustainability. Qualitative data should also be collected to investigate how the programme would help the patients to improve their diabetes care. More objective measurement on exercise level by pedometer and 1 week food diary for nutritional assessment would be used to measure those behaviours reflecting diet and exercise.

\section{CONCLUSION}

This randomised controlled trial of diabetes self management concentrating on self efficacy and development of a healthy 
behavioural model has demonstrated statistically significant changes in clinical outcomes and health behaviours in the experimental group. Energy and effort should be invested in patient self management to support patients to live with the best possible control of their chronic condition. A recent editorial by Lehman and Krumholz argued that tighter glycaemic control in all patients with type $2 \mathrm{DM}$ regardless of duration of diabetes and the drugs being used would lead to a waste of resources and possible harm to patients. ${ }^{40}$ GPs should reinforce self management to avoid patients with chronic illnesses socialised into the medical model fostering a dependence on professionals, and should also advocate for patients to appeal to healthcare providers and health insurers to include patient self management as part of formal healthcare. Raising self efficacy and self construction of a healthy behavioural model is feasible and acceptable in the general practice setting and also in an oriental culture with a dominance of doctor centred care.

Funding Other funders: self funded.

Competing interests None.

Patient consent Obtained.

Ethics approval The study was approved by The Chinese University of Hong Kong and Hospital Authority NT East Cluster Clinical Research Ethics Committee. CRE-2007, 136-T.

Contributors AL was responsible for study design and planning, supervision of data collection, wrote the manuscript, contribution to discussion and revision of manuscript. CFS was responsible for study design, research data, and contribution to discussion, reviewed and edited. KTL was responsible for study design, research data, and contribution to discussion, reviewed and edited. LCHL, CCMC, KKW were responsible for research data, and reviewed and edited. KKW is overall in charge of statistical analysis. AL is the guarantor of the study.

Provenance and peer review Not Commissioned; externally peer reviewed.

\section{REFERENCES}

1. Turner RC, Milins H, Neil HA, et al. Risk factors for coronary heart disease in noninsulin dependent diabetes mellitus: United Kingdom Prospective Diabetes Study (UKPDS: 23). BMJ 1998;316:823-8.

2. Anon. Efficacy of atenolol and captorpil in reducing risk of macrovascular and microvascular complications in type 2 diabetes: UKPDS 39. UK Prospective Diabetes Study Group. BMJ 1998;317:713-20.

3. Gerstein HC, Miller ME, Byington RP, et al; Action to Control Cardiovascular Risk in Diabetes Study Group. Effects of intensive glucose lowering in type 2 diabetes. N Engl J Med 2008;358:2545-59.

4. Patel A, MacMohan S, Chalmers J, et al; ADVANCE Collaborative Group. Intensive blood glucose control and vascular outcomes in patients with type 2 diabetes. $N$ Engl J Med 2008;358:2560-72.

5. Bonds DE, Miller ME, Bergenstal RM, et al. The association between symptomatic, severe hypoglycaemia and mortality in type 2 diabetes: retrospective epidemiological analysis of the ACCORD study. BMJ 2010;340:b4909.

6. Miller ME, Bond DE, Gerstan $\mathrm{HC}$, et al. The effects of baseline characteristics, glycaemia treatment approach, and glycated haemoglobin concentration on the risk of severe hypoglycaemia: post-hoc epidemiological analysis of the ACCORD study. BMJ 2010;340:b5444.

7. Norris SL, Engelgau MM, Narayan KM. Effectiveness of self-management training in type 2 diabetes: a systematic review of randomised controlled trials. Diabetes Care 2001;24:561-87

8. Wagner EH, Austin BT, Von Korff M. Organising care for patients with chronic illness. Midbank 0 1996:74:511-44.

9. Havas S. The ACCORD Trial and control of blood glucose level in type 2 diabetes mellitus: time to challenge conventional wisdom. Arch Intern Med 2009;169:150-4.

10. Steed L, Cooke D, Newman S. A systematic review of psychological outcomes following education, self-management and psychological interventions in diabetes mellitus. Patient Educ Couns 2003:51:5-15.

11. Lorig K. Self-management education: more than a nice extra. Med Care 2003;41 (6):699-701.

12. McKay HG, King D, Eakin EG, et al. The diabetes network internet-based physical activity intervention: a randomised pilot study. Diabetes Care 2001;24:1328-34.
13. Department of Health and Human Services (US). Healthy People 2010: Understanding and Improving Health. http://www.healthypeople.gov/.

14. Lorig K, Ritter PL, Plant K. A disease-specific self-help programme compared with a generalized chronic disease self-help programme for arthritis patients. Arthritis Rheum 2005;53:950-7.

15. Bandura A. Self-efficacy mechanism in psychobiologic functioning. In: Schwarzer R, ed. Self-Efficacy: Thought Control of Action. Washington, DC: Hemisphere, 1992:355-94.

16. Furler $\mathbf{J}$, Walker $\mathrm{C}$, Blackberry I, et al. The emotional context of self-management in chronic illness: a qualitative study of the role of health professional support in the self-management of type 2 diabetes. BMC Health Serv Res 2008;8:214. http://www. biomedcentral.com/1472-6963/8/214.

17. Roger A. Demand by faint praise? Chronic Illness 2006;2:262-4.

18. Walker C, Peterson C, Millen N. A proposal for a new model of chronic illness. In: Walker C, Peterson C, Millen N, et al, eds. Chronic Illness: New Perspectives and New Directions. Victoria Australia: Tertiary Press, 2003:17-35.

19. Lorig KR, Sobel DS, Ritter PL, et al. Effect of s self-management program on patients with chronic disease. Eff Clin Pract 2001;4:256-62.

20. The Expert Patient: A New Approach to Chronic Disease Management for the 21st Century. http://www.dh.gov.uk/assetRoot/04/01/85/78/04018578.pdf.

21. Peeples M, Tomky D, Mulcachy K, et al. Evolution of the American Association of Diabetes Educators' diabetes education outcomes project. Diabetes Educ 2007:33:794-819

22. Minet L, Moller S, Vach W, et al. Mediating the effect of self-care management intervention in type 2 diabetes: a meta-analysis of 47 randomised controlled trails. Patient Educ Couns 2010;80:29-41.

23. Siu CF, Chou KL. The Psychometric Properties of the Diabetes Management SelfEfficacy Scale for Patients with Type 2 Diabetes Mellitus in Hong Kong. 8th Hong Kong Diabetes and Cardiovascular Risk Factors - East Meets West Symposium. Hong Kong: Hong Kong Institute of Diabetes and Obesity, Hong Kong Foundation for Research and Development in Diabetes, Asian Pacific Society of Atherosclerosis and Vascular Diseases and Hong Kong Atherosclerosis Society, 2006.

24. DoH. Population Health Survey. Department of Health in Hong Kong, 2003/2004.

25. Lee A, Lo A, Ho M. Central and Western Healthy City: Community Diagnosis. Centre for Health Education and Health Promotion, The Chinese University of Hong Kong and Central and Western District Council, 2009.

26. Chin MH, Cook S, Drum ML, et al. Improving diabetes care in midwest community health centers with the health disparities collaborative. Diabetes Care 2004:27:2-8.

27. Bodenheimer T, Wagner $E H$, Grumback K. Improving primary care for patients with chronic illness: the chronic care model, part 2. JAMA 2002;288:1909-14.

28. Farmer A, Ward A, Goyder E, et al. Impact of self monitoring of blood glucose in the management of patients with non-insulin treated diabetes: open parallel group randomised trial. BMJ 2007:335:132.

29. Day JL, Coles C, Watford S. Self-management in diabetes: training implications for professional carers. Clin Med 2003;3:338-41.

30. Glasgow RE, Toobert DJ, Hampson SE. Participation in outpatient diabetes education program: how many patients take part and how representatives are they? Diabetes Educ 1991;17:376-80.

31. Cater IR, Nash C, Ridgway A. On any saturday-a practical model for diabetes education. J Natl Med Assoc 2002;94:67-22.

32. Greene J, Yedidia MJ. Take Care to Learn Evalutation Collaborative. Provider behaviors contributing to patient self-management of chronic illness among underserved populations. J Health Care Poor Underserved 2005;16:808-24

33. Blakeman $\mathbf{T}$, MacDonald W, Bower $P$, et al. A qualitative study of GPs' attitudes to self-management of chronic disease. Br J Gen Pract 2006:56:407-14.

34. Rose V, Harris M, Ho MT, et al. A better model of diabetes self-management? Interactions between GP communication and patient self-efficacy in self-monitoring of blood glucose. Patient Educ Couns 2009;77:260-5.

35. Sperl-Hillen J, O'Connor PJ, Carlson RR, et al. Improving diabetes care in a large healthcare system: an enhanced primary care approach. Jt Comm J Qual Improv 2000;26:615-22

36. Bodenheimer T, Lorig $\mathrm{K}$, Holman $\mathrm{H}$. Patient self-management of chronic disease in primary care. JAMA 2002;288:2469-75.

37. Raguenaud ME, Issakidis $P$, Reid T, et al. Treating 4,000 diabetic patients in Cambodia, a high prevalence but resource-limited settings: a 5 year study. BMC Med 2009; 7:33

38. Tang TS, Funnel MM, Brown MB, et al. Self-management support in "real-world" settings: an empowerment-based intervention. Patient Educ Couns 2010;79:178-84

39. Davies MJ, Hellwer S, Campbell MJ, et al. Effectiveness of the diabetes edcuation and self-management for on-going anf newly diagnosed (DESMOND) programme for people with newly diagnosed type 2 diabetes: cluster randomised controlled trail. BMJ 2008;336:491-5.

40. Lehman R, Krumholz HM. Tight control of blood glucose in long standing type 2 diabetes. BMJ 2009;338:b800. 